\title{
The reduction of 2- and 3-ring PAHs entering to the surface waters in the integrated processes
}

\author{
Maria Włodarczyk-Makuła ${ }^{1, *}$, and Agnieszka Popenda ${ }^{1}$ \\ ${ }^{1}$ Czestochowa University of Technology, 42-200 Czestochowa, Poland
}

\begin{abstract}
The aim of the study was to determine the removal of 2- and 3-ring polycyclic aromatic hydrocarbons (PAHs) during oxidation process and during simultaneous oxidation and adsorption processes. Technological research was conducted with the use of biologically treated industrial wastewater. Oxidation was carried out with dihydrogen peroxide. The adsorption process was carried out onto activated carbon. Quantitative and qualitative determination of polycyclic aromatic hydrocarbons was conducted using gas chromatograph and mass spectrometer system. The experiments were conducted under constant $\mathrm{pH}$ as well asunder the constant temperature. The oxidation efficiency of the analyzed hydrocarbons under oxidation conditions ranged from 14 to $81 \%$. During the simultaneous oxidation process and adsorption on activated carbon, the PAHs removal ranged from 43 to $100 \%$. The results lead to the conclusions that simultaneous oxidation and adsorption can be successfully apply in the final treatment of industrial wastewater resulting in the minimizing PAHs load entering to the surface waters.
\end{abstract}

\section{Introduction}

Recently, in technology wastewater most often the third step of wastewater treating by applying additional processes is of high importance. The attention is paid into increasing the level of removal both organic and inorganic pollutants resulting in lowering the load of pollutants entering to the surface waters. That is important because surface waters are the sources of water in the municipal administration systems. In current legislations the presence of organic micropollutants, such as: polycyclic aromatic hydrocarbons (PAHs) is omitted [1]. On the other hand PAHs are listed among contaminants that should be removed from wastewater due to their carcinogenic and mutagenic properties. So far, the investigations into treated wastewater have indicated that although the high level of wastewater treatment is obtained, the efficiency removal of PAHs is low [2,3]. This phenomenon was observed both in municipal and industrial wastewater. With respect to industrial wastewater the certain load of micropollutants is removed in the industrial factories however, more strict requirements of environmental quality force the application of methods and processes in the removal or decomposition of entering to the receiver pollutants. It is mainly aimed to organic pollutants, such as: polycyclic aromatic hydrocarbons (PAHs), organic chlorine derivatives or colouring agents $[4,5]$. Some of them have carcinogenic and mutagenic influence on the organisms as well as they are relative persistent in the environment.

The literature studies and own investigations indicate that is possible to apply sorption as well as advanced oxidation processes (AOP) with respect to PAHs removal [6-9]. Considering sorption process the activated carbons, including these obtained from various waste materials, are mostly applied in the removal of PAHs. Among wide range of the literary sources regarding sorption of organic substances onto activated carbons the limited information can be found of the applying sorption in the removal of PAHs from wastewater [6,10]. The available literature [11-15] confirm that activated carbons may be successfully apply in the removal of organic compounds from the water solutions. It should also be highlighted that in the water solutions, such as: waters, wastewater, soil-water environment the mixture of various organic compounds appears resulting in the limited efficiency of sorption of selected compounds due to the possibility of the presence of competitive sorption and suspensions. Therefore, it is searching for alternative methods of removal of organic compounds from the water solutions including oxidation in the advanced oxidation processes $[16,17]$. The literary data $[9,18-20]$ confirm the high efficiency of AOP in the removal of organic substances especially resistant to the biodegradation. The fundamentals of the afore mentioned methods is oxidation of most organic compounds to the $\mathrm{CO}_{2}, \mathrm{H}_{2} \mathrm{O}$ with the usage of radicals hydroxyl $\mathrm{OH} \bullet$. Dihydrogen dioxide or a compound of Fenton's reagent is one of the oxidants that can be apply in the AOP processes [21-23]. The application of Fenton's reaction in the oxidation of selected PAHs was carried out in the studies of RubioClemente [24]. So far, the investigations aiming the advanced oxidation of PAHs have been conducted on model solutions containing individual or no more than few hydrocarbons. It should be highlighted that PAHs

Corresponding author: mwm@is.pcz.czest.pl 
are present in the environment as mixtures of various composition. In the literary there is also information available of the studies of the removal organic compounds in two-step process - oxidation and sorption. It is described the primary removal of organic compounds in the sorption, and then oxidation of adsorbed substances. Simultaneous sorption and oxidation can be regarded as another system of integration the afore mentioned processes. In this case adsorbent (e.g. activated carbon) plays the role of sorbent of organic compounds as well as catalyst of radicals hydroxyl formation responsible for the oxidation of organic substances: dissolved and adsorbed compounds $[17,23]$. Although many investigations into advanced oxidation processes and adsorption have been carried out up, the decomposition of PAHs in the industrial wastewater under oxidation in the presence of activated carbon has not been considered so far. Due to the satisfactory effects of the removal/degradation of PAHs both during the sorption and oxidation the studies aiming the determination of removal efficiency of hydrocarbons by combing both process have been undertaken $[3,4,23,24]$.The aim of the work was to determine the removal efficiency of 2- and 3-ring PAHs during simultaneously conducted oxidation with dihydrogen dioxide and sorption on activated carbon.

\section{Methodology of technological studies}

\subsection{Material and methodology of conducting investigations}

The technological studies were carried out using biologically treated coke-plant wastewater. The wastewater samples were taken once. In raw wastewater samples the initial organic content was determined by chemical oxygen demand (COD) as well as PAHs. It should be noted that coke wastewater originating from the technological processes enter to the biological wastewater treatment plant working with activated sludge and the nitrification of ammonia nitrogen removal. The technological studies were carried out with the usage of strong oxidant dihydrogen dioxide (30\%). The dose of the oxidant equal to $10 \mathrm{ml} / \mathrm{L}$ was formerly adjusted [24,25]. The sorption was carried out using activated carbon. The time of carrying the simultaneous process of oxidation and adsorption was constant and equal to 1 hour. Then, the concentration of selected hydrocarbons and organic content expressed as COD was determined.

\subsection{Analytical methods of PAHs}

In order to determine PAHs, the initially preparation of wastewater samples was performed during extraction of organic substances by liquid-liquid method. Mixture of cyclohexane and dichlomethane $(\mathrm{v} / \mathrm{v}-5: 1)$ was added to the wastewater samples. Samples containing activated carbon were filtered and then both solution and suspension samples were analyzed. In this case to the suspension the mixture of the afore mentioned solvents was added. Then, the extraction was conducted by shaking liquid samples or filters containing suspension on the linear shaker within 1 hour. Afterwards, the extract was separated in glass classifier by flushing the walls few times or by decanting from the filter. Then, anhydrous sulphate sodium was added in order to bind to the remaining wastewater. Afterwards, the purification of extracts on silica gel in SPE Baker chamber was made. The purified extracts were concentrated under nitrogen stream to the volume of $2 \mathrm{ml}$. The prepared extracts were analyzed using gas chromatograph with mass spectrometry (Fisons) system. The time of analysis was equal to 50 minutes. The flow rate of samples was $1,5 \mathrm{ml} / \mathrm{min}$. The recovery values were determined for individual PAHs, and then the average concentration of the following PAHs: naphtalene, acenaphtylene, acenaphtene, fluorene, phenanthrene and anthracenewas calculated. The mentioned compounds include from 12 to 14 carbon atoms in the particle or 12 hydrogen atoms. They have rather low octanol/water partition coefficient.

\section{Results and discussion}

The content of organic compounds in wastewater taken from the coke wastewater treatment plant expressed by COD was on the level of $1412 \mathrm{mg} / \mathrm{L}$, whereas $\mathrm{pH}$ was equal to 6.8. After the process of oxidation COD decreased to the value of $1046 \mathrm{mg} / \mathrm{L}$. The initial concentration of naphthalene ranged the value of $2270 \mu \mathrm{g} / \mathrm{L}$. The changes in the naphthalene concentration during studies are included in Fig. 1.

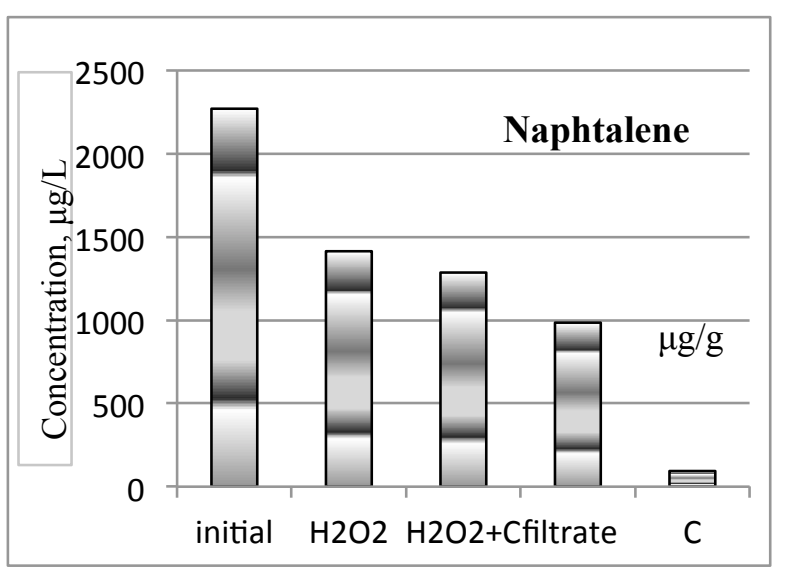

Fig. 1. Changes in the naphtalene concentration during oxidation and adsorption processes.

The efficiency of the naphtalene removal during oxidation and adsorption processes achieved $38 \%$ and $43 \%$, respectively. The PAHs determination was carried out after filtering samples resulting in the isolation of dissolved fraction and suspension of activated carbon. The amount of naphtalene extracted from activated carbon was equal to $96 \mu \mathrm{g} / \mathrm{g}$ C. The initial total concentration of 2-benzene ring hydrocarbons and one cyclopenthane ring ranged the value of $10523 \mu \mathrm{g} / \mathrm{L}$. After adding dihydrogen dioxide and PAHs oxidation the $77 \%$ decrease of hydrocarbons was noted. However, the 
efficiency degradation of individual compounds was diversified. The structure of acenaphtylene was stable resulting in the concentration before and after process only of $23 \%$ lower than the initial one. During simultaneous processes of oxidation and adsorption the decrease in the acenaphtylene content ranged $80 \%$. Changes in the acenaphtylene concentration during oxidation and adsorption processes are given in Fig. 2 .

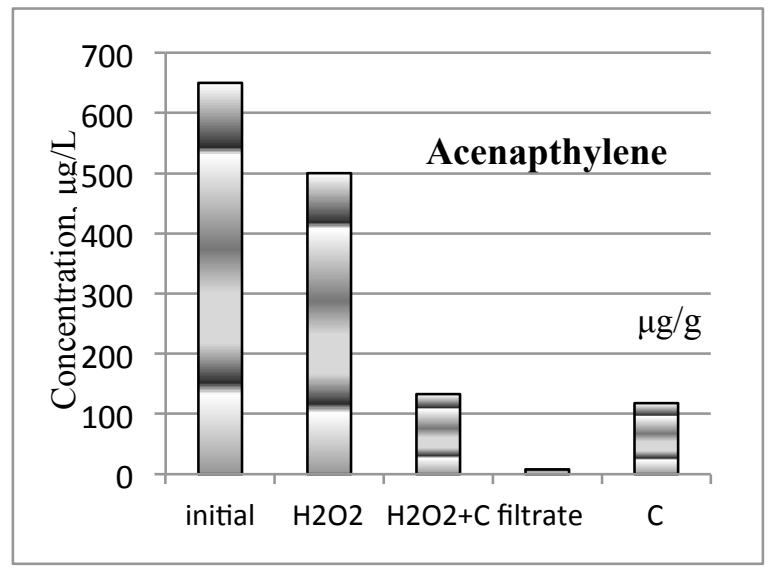

Fig. 2. Changes in the acenaphtylene concentration during oxidation and adsorption processes.

In Fig. 3 and 4 changes in the concentration of acenaphtylene and fluorine during oxidation process are included, respectively.

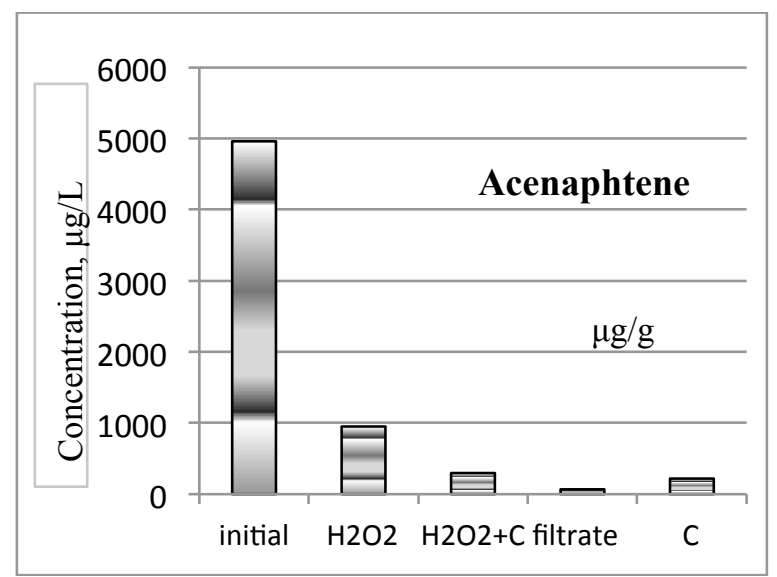

Fig. 3. Changes in the acenaphtene concentration during oxidation and adsorption processes.

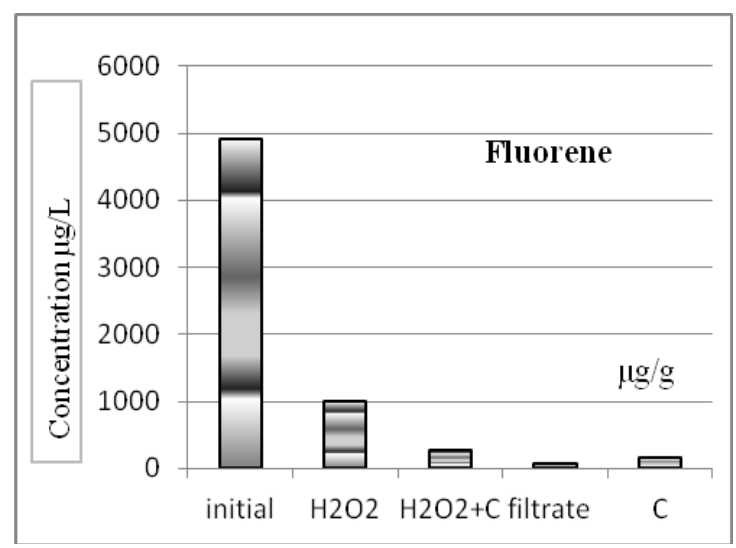

Fig. 4. Changes in the fluorene concentration during oxidation and adsorption processes.
In contrast to acenaphtylene, the content of acenaphtene and fluorene was lower than the initial one of $80-81 \%$. In simultaneous adsorption and oxidation process the decrease of PAHs was higher than in the case of oxidation and ranged the value of $94 \%$. The PAHs determination was carried out after filtering, isolating dissolved fraction and suspension of activated carbon. The total concentration of three compounds amounted $146 \mu \mathrm{g} / \mathrm{L}$ and was lower of $98 \%$ from the initial one.

Extraction of PAHs from the suspension allowed to determine compounds that were adsorbed onto activated carbon. The concentration of three 3-ring compounds on activated carbon suspension ranged the value of 509 $\mu \mathrm{g} / \mathrm{g} \mathrm{C}$. That indicates of the high importance of sorption despite the high solubility in the water. The total concentration of 3-ring hydrocarbons did not exceed the value of $3600 \mu \mathrm{g} / \mathrm{L}$.

In Fig. 5 and Fig. 6 changes in the phenanthrene anthracene concentration during studies are given, respectively. After oxidation with the usage of dihydrogen dioxide the total concentration was lower than the initial one of $47 \%$. The addition of activated carbon improved the efficiency of PAHs removal of $26 \%$. In the filtered samples the PAHs concentration was lower than the initial one of $90 \%$.

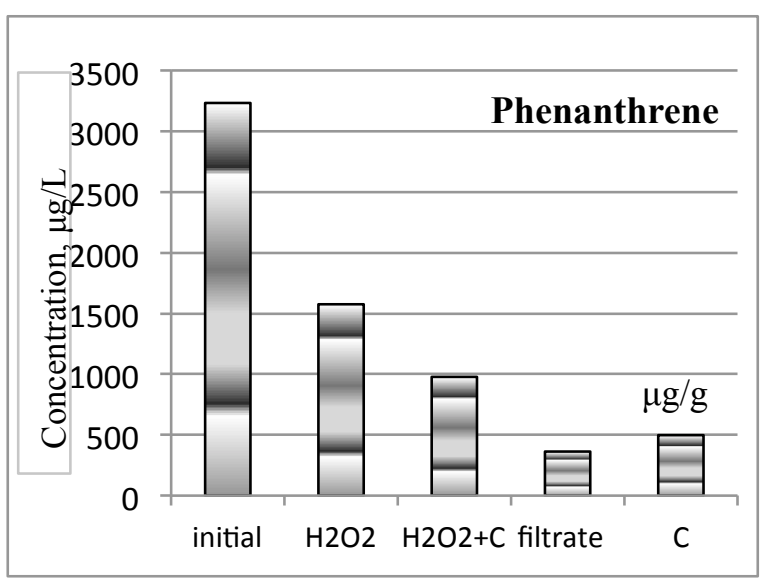

Fig. 5. Changes in the phenanthrene concentration during oxidation and adsorption processes.

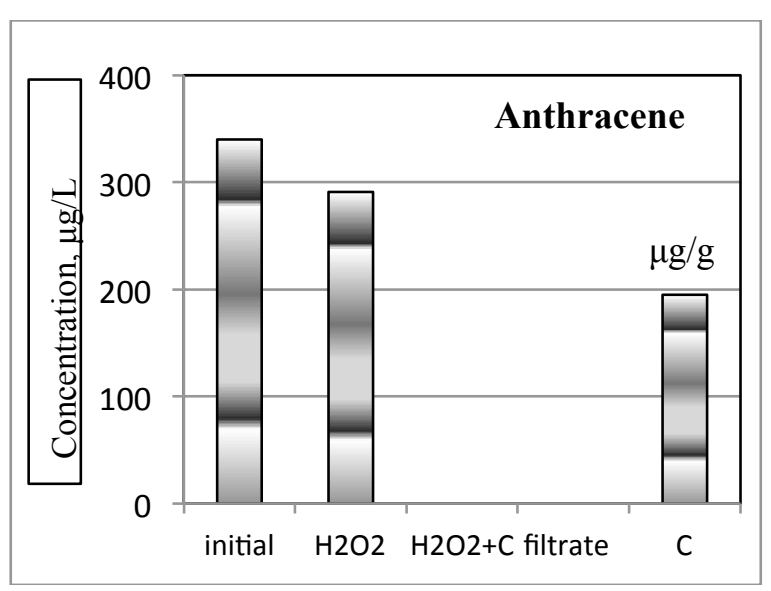

Fig. 6. Changes in the anthracene concentration during oxidation and adsorption processes.

From the activated carbon $700 \mu \mathrm{g} / \mathrm{g} \mathrm{C}$ of PAHs were extracted. The results indicate that more favorable 
conditions of 2- and 3-ring hydrocarbons removal appeared during simultaneous oxidation and adsorption. It should be noted that under technological conditions of carrying studies the highest level of the decrease was found for hydrocarbons including cyclopenthane ring in the particle structure.

\section{Conclusions}

Based on the conducted studies the following conclusions can be formulated:

- The efficiency of degradation of studied hydrocarbons was in the range of $14-81 \%$ under oxidation whereas, under simultaneous oxidation and adsorption onto activated carbon was in the range of $43-100 \%$, respectively.

- Simultaneous oxidation and adsorption may be effectively apply in the additional treatment of wastewater including PAHs.

The studies were supported byBS-PB-402-301/11

\section{References}

1. Rozporzadzenie Ministra Środowiska z dnia 18 listopada 2014 r., Dz. U. 2014 poz. 1800

2. M. Włodarczyk-Makuła, Physical and Chemical Fates of organic micropollutants (Scholar-Press, 2015)

3. M. Włodarczyk-Makuła, Ann. Set Environ. Prot. 13, (2011)

4. M. Włodarczyk-Makuła, A. Turek, Monografie Komitetu Inżynierii Środowiska Polskiej Akademii Nauk (Polska Akademia Nauk, 2012)

5. L. Dąbek, E. Ozimina, A. Picheta-Oleś, Annu. Set Environ. Prot. 15, (2013)

6. M. Smol, M. Włodarczyk-Makuła, D. Włóka, CEER 13, 2 (2014)

7. E. Ayranci, O. Duman, Chem. Eng. J. 156 ( 2010)

8. R.C.Brandli, T. Hartnik, T. Henriksen, G. Cornelissen, Chemosphere 73, 11 (2008)

9. K. Barbusiński, Aktualne Zagadnienia $W$ Uzdatnianiu I Dystrybucji Wody(Wydawnictwo Politechniki Śląskiej, Gliwice, 2013)

10. M. Smol, D. Włóka, M. Włodarczyk-Makuła, Water Air Soil Pollut. 229, 154 (2018)

11. B. Pan, X. Baoshan, Environ. Sci. Technol. 42, 24 (2008)

12. H.H. Huang, M.C. Lu, J.N. Chen, C.T. Lee, Chemosphere 51 (2003)

13. M.A. Nkansah, A.A. Christy, T. Barth, G.W. Francis, J. Hazard. Mater. 217 (2012)

14. M. Yuan, S. Tong, S. Zhao, C.Q. Jia, J. Hazard. Mater. 181, 1 (2010)

15. F. Beltrán, J. Rivas, P. Álvarez, M. Alonso, B. Acedo, Ind. Eng. Chem. Res. 38 (1999)

16. A. Kornmüller, U. Wiesmann, Water Res. 37 (2003)
17. M. Trapido, Y. Veressinina, R. Munter, Environ. Technol. 16 (1995)

18. E. Neyens, J. Baeyens, J. Hazard. Mater. B98 (2003)

19. S.R. Pouran, A. Abdul, R. Abdul, M. Wan, W.D. Ashri, J. Clean Prod. 64 (2014)

20. A.N. Soon, B.H. Hameed, Desalin. 269 (2011)

21. L.C. Toledo, A.C. Silva, R. Augusti, R.M. Lago, Chemosphere 50 (2003)

22. A. Rubio-Clemente, R.A. Torres-Palma, G.A. Penuela, Sci. Total Environ. 478 (2014)

23. A. Turek, M. Włodarczyk-Makuła, W.M. Bajdur, Desalin. Water Treat. 57, 3 (2016)

24. A. Turek, M. Włodarczyk-Makuła, A. Nowacka, Ann. Set Environ. Prot. 16 (2014) 